\title{
Desempenho logístico de embalagens para molho de tomate: um estudo de caso na cidade de São Paulo, Brasil
}

\section{Logistical performance of tomato sauce packaging: a case study in São Paulo, Brazil}

Ana Paula Reis Noletto ${ }^{1 *}$ (1), Sérgio Adriano Loureiro², Danielle Ito, Orlando Fontes Lima Júnior ${ }^{2}$

${ }^{1}$ Instituto de Tecnologia de Alimentos (ITAL), Centro de Tecnologia de Embalagem (CETEA), Campinas/SP - Brasil 2Universidade Estadual de Campinas (UNICAMP), Faculdade de Engenharia Civil, Departamento de Geotecnia e Transportes, Laboratório de Aprendizagem em Logística e Transportes (LALT), Campinas/SP - Brasil

${ }^{*}$ Corresponding Author: Ana Paula Reis Noletto, Av. Brasil, 2880, CEP: 13070-178, Campinas/SP - Brasil, e-mail: anapaula@ital.sp.gov.br

Cite as: Noletto, A. P. R., Loureiro, S. A., Ito, D., \& Lima Júnior, O. F. Logistical performance of tomato sauce packaging: a case study in São Paulo, Brazil. Brazilian Journal of Food Technology, 22, e2018121.

https://doi.org/10.1590/1981-6723.12118

\begin{abstract}
Resumo
As cadeias de suprimentos de alimentos estão intrinsecamente ligadas à presença das embalagens, uma vez que estas são imprescindíveis para garantir a proteção e a preservação de alimentos dos centros de produção até o consumidor. Além disso, as embalagens facilitam as etapas de manuseio, transporte e armazenagem, tendo como consequências a melhoria das operações e a redução de custos. $\mathrm{O}$ objetivo deste estudo foi avaliar o desempenho de três diferentes embalagens para acondicionamento de molho de tomate (lata, stand-up pouch e embalagem cartonada) em relação à logística de distribuição na área urbana. Para essa avaliação, foi utilizada a metodologia Packaging Scorecard, na qual são entrevistados os profissionais presentes ao longo da distribuição desses produtos. Os resultados mostraram que, para a cadeia de suprimentos estudada, a lata apresentou o melhor desempenho global. A embalagem cartonada apresentou desempenho global muito próximo ao da lata, tendo melhor desempenho em três dos quatro locais de avaliação. Além disso, os resultados obtidos oferecem uma visão sistêmica da cadeia, com a identificação de pontos críticos das embalagens, e podem ser utilizados pelos profissionais dos diferentes locais de distribuição visando à melhoria do desempenho logístico das embalagens.
\end{abstract}

Palavras-chave: Embalagem; Logística; Cadeia de suprimentos; Derivado de tomate; Packaging scorecard; Distribuição urbana.

\begin{abstract}
Food supply chains are intrinsically linked to the presence of packaging, since they are essential to ensure the food protection and preservation from the production centers to the consumer. In addition, the packaging favors handling, transport and storage steps resulting in improved operations and reduced costs. The objective of this study was to evaluate the performance of three different tomato sauce packaging (can, stand-up pouch and carton pack) in relation to distribution logistics in urban area. The Packaging Scorecard methodology was used in this
\end{abstract}


study, in which the professionals present during the distribution of these products were interviewed. The results showed that, for the studied supply chain, the can presented the best overall performance. The carton packaging presented a similar overall performance compared to the can, performing better in three of the four evaluation sites. In addition, the obtained results provide a systemic view of the chain, identifying the critical points of the packaging, and may be used by professionals of the different distribution sites aiming improvement in the packaging logistics performance.

Keywords: Packaging; Logistics; Supply chain; Tomato products; Packaging scorecard; Urban distribution.

\section{Introdução}

O aumento da concentração da população nas áreas urbanas tem se tornado uma realidade nas grandes cidades de vários países, nas últimas décadas. Em paralelo a esse crescimento, houve uma mudança no comportamento do consumidor, que busca encontrar mais rapidamente, e de forma centralizada, produtos e serviços (Dezi et al., 2010). Essa ocupação maciça das áreas urbanas gera um aumento no número de veículos de passeio e de carga que transitam nessas áreas, dificultando a circulação e comprometendo a eficiência da distribuição física de bens.

O transporte e a distribuição fazem parte das principais atividades logísticas ao longo das cadeias de suprimentos de alimentos e, nessas etapas, as embalagens podem atuar, entre outras formas, como agentes de otimização das operações, reduzindo os tempos de permanência dos veículos em carga e descarga, e, consequentemente, melhorando o tráfego urbano de carga.

Segundo Nilsson et al. (2013), as embalagens estão sendo consideradas a mais importante interface entre os produtos e os sistemas logísticos. Para Lockamy III (1995) e Chan et al. (2006), os principais objetivos de um desenvolvimento de uma embalagem devem contemplar: a proteção do produto; a adequação ao sistema de distribuição; a avaliação das necessidades ergométricas, e o atendimento às informações referentes aos produtos.

As características dimensionais das embalagens devem proporcionar a melhor relação de ocupação de produto/embalagem e embalagem/modal de transporte, com consequente redução dos custos de transportes.

Os estudos sobre a importância da embalagem no sistema de distribuição de produtos abrangem o conceito de Packaging Logistics, definido como a criação ou o desenvolvimento de embalagens e sistemas de embalagens, visando, além da proteção ao produto, ao apoio aos objetivos da logística de planejar, implementar e controlar de maneira eficaz e eficiente o fluxo de materiais (Johansson et al., 1997; GarcíaArca et al., 2017).

Dentro desse contexto, o objetivo deste artigo foi avaliar o desempenho logístico de três sistemas de embalagens para acondicionamento de molho de tomate, com distribuição ocorrendo na cidade de São Paulo. Diferentes sistemas de embalagens podem apresentar variação de performance em relação a redução de perda de alimentos e agilidade nas movimentações, as quais ocorrem ao longo das cadeias de distribuição, gerando melhorias ambientais, econômicas e sociais.

\subsection{Embalagem e logística}

A importância da embalagem como um agente de melhoria da logística de distribuição de bens é cada vez mais reconhecida. Na medida em que é imprescindível para garantir a proteção e a preservação de bens de consumo dos centros de produção até o consumidor, a embalagem também atua como uma facilitadora das etapas de manuseio, movimentação e armazenagem, e possibilita a redução de custos (Arvanitoyannis, 2008; Rundh, 2013). 
A Tabela 1 apresenta as relações entre uma especificação adequada de embalagens e seu impacto nas atividades logísticas (Lambert et al., 1998; Peres, 2006).

Tabela 1. Melhorias na embalagem versus atividades logísticas.

\begin{tabular}{|c|c|c|}
\hline $\begin{array}{c}\text { Embalagem com especificação } \\
\text { correta }\end{array}$ & $\begin{array}{l}\text { Atividade } \\
\text { Logística }\end{array}$ & Impacto \\
\hline \multirow{3}{*}{$\begin{array}{c}\text { Informações adequadas } \\
\text { Melhores características de } \\
\text { proteção }\end{array}$} & \multirow{4}{*}{ Transporte } & Redução do tempo de expedição \\
\hline & & $\begin{array}{l}\text { Redução dos custos de movimentação e tempo de } \\
\text { espera }\end{array}$ \\
\hline & & $\begin{array}{l}\text { Redução do uso de equipamentos especiais no } \\
\text { transporte }\end{array}$ \\
\hline Maior nível de padronização & & $\begin{array}{l}\text { Otimização de uso de espaço dos meios de } \\
\text { transportes }\end{array}$ \\
\hline \multirow{2}{*}{$\begin{array}{c}\text { Informações adequadas } \\
\text { Melhores características de } \\
\text { proteção }\end{array}$} & \multirow{3}{*}{ Armazenagem } & $\begin{array}{l}\text { Diminuição do tempo de efetivação de pedidos e } \\
\text { redução de mão-de-obra }\end{array}$ \\
\hline & & $\begin{array}{c}\text { Otimização de uso de espaço de Centros de } \\
\text { Distribuição }\end{array}$ \\
\hline Maior nível de padronização & & $\begin{array}{l}\text { Custos direcionados para equipamentos de } \\
\text { movimentação adequados }\end{array}$ \\
\hline
\end{tabular}

Kye et al. (2013) identificam quatro características das embalagens que impactam diretamente na eficiência do transporte de carga: a) a padronização das caixas de embarque; b) o controle de modelos de paletes utilizados na distribuição da carga (exemplo: paletes PBR $1000 \times 1200 \mathrm{~mm}$ ); c) o uso de sistemas de embalagens que facilitem as operações de logística reversa; d) presença de informações que possibilitem a rastreabilidade e propiciem a visibilidade e segurança dos produtos, ao longo da cadeia de suprimentos.

No Brasil, uma boa parte dos alimentos produzidos é enviada a regiões distantes de suas áreas de produção. Para que estes sejam entregues em grandes quantidades e de forma segura, surge a necessidade da formação das unidades de carga (paletização da carga). Através de caminhões de grande porte, esses produtos chegam aos grandes centros urbanos e, para que ocorra a entrega aos varejistas, estas unidades de carga devem ser fracionadas para distribuição em veículos de menor porte.

O fracionamento da carga solicita ainda mais um bom desempenho das embalagens de transporte (exemplo: caixas de embarque) e das embalagens primárias (latas, embalagens cartonadas e stand up pouch), uma vez que a condição original/ideal para o transporte dessas embalagens pode ser alterada com o uso de cargas mistas e/ou não unitizadas, dependendo do veículo de carga urbana (VUC) utilizado.

Uma vez que a embalagem foi desenvolvida e lançada no mercado, uma das grandes dificuldades encontradas pelos profissionais de engenharia de embalagem é a mensuração de sua eficiência dentro das cadeias logísticas. A utilização de uma ferramenta para avaliação do desempenho de um sistema de embalagem, sob a ótica dos vários profissionais envolvidos na distribuição de um produto, possibilita a implantação de melhorias, com redução de perdas de alimentos e de custos operacionais.

\subsection{Embalagens para molho de tomate}

Os produtos atomatados (que compreendem a família dos molhos, purês, extratos e catchups) têm apresentado várias opções de embalagem primária. No Brasil, as embalagens primárias mais utilizadas para acondicionamento de molhos de tomates são as latas, as embalagens cartonadas (tipo longa vida) e os stand up pouches (Supermercado Moderno, 2016). O consumo de molhos de tomate em embalagens stand up pouches vem aumentando nos últimos anos, impulsionado principalmente pelos consumidores das classes $\mathrm{D}$ e E, que buscam o menor preço oferecido pelo produto nessa embalagem (Sousa, 2013). 


\section{Material e métodos}

Foi avaliado o desempenho de três sistemas de embalagem para molho de tomate: lata, embalagem cartonada e stand up pouch. A cadeia de distribuição do produto ocorre de duas formas, dependendo das características do Ponto de Venda. As Figuras 1 e 2 ilustram estas duas cadeias:

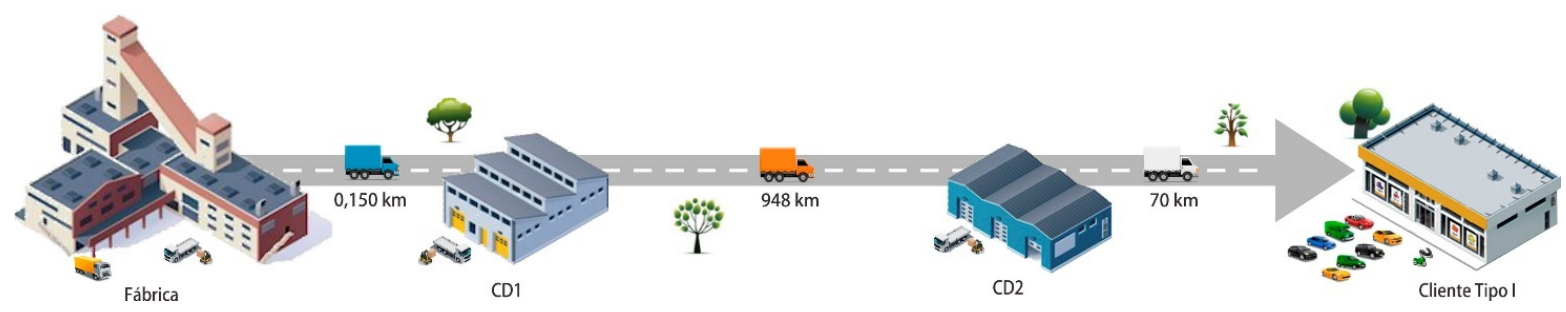

Figura 1. Perfil da cadeia de distribuição para os clientes do tipo Ponto de Venda Varejista (PVV).

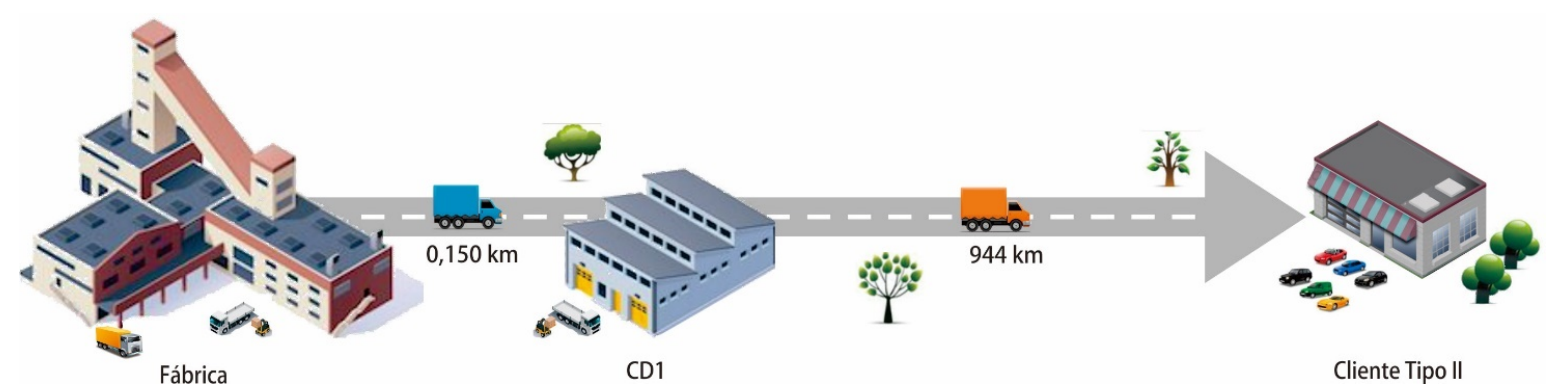

Figura 2. Perfil da cadeia de distribuição para os clientes do tipo Ponto de Venda Atacadista (PVA).

Conforme ilustrado nas Figuras 1 e 2, independentemente do destino final, os produtos saem da fábrica e são estocados em um Centro de Distribuição (CD1) próximo. A partir do CD1, ocorre uma diferenciação de distribuição. Para os clientes do tipo Ponto de Venda Atacadista, a carga é enviada diretamente do CD1 para o PVA. Para os clientes do tipo Ponto de Venda Varejista, a carga é enviada ao CD2, onde ocorre a separação e o envio do pedido feito pelo PVV, além da segregação de embalagens avariadas. Todos os Pontos de Venda estavam localizados na cidade de São Paulo.

\subsection{Materiais}

Foi avaliada uma marca de molho de tomate, produzido por fabricante nacional e acondicionada em três diferentes tipos de embalagens primárias:

a) Embalagem metálica: Lata de folha de flandres, de três peças, com sistema de abertura abre-fácil - 340g. Embalagem secundária: Bandeja de papelão ondulado, contendo 24 latas, envolvida por filme plástico termoencolhível;

b) Embalagem cartonada: Asséptica, tipo longa vida - 520g. Embalagem secundária: Bandeja de papelão ondulado, contendo 12 embalagens cartonadas, envolvida por filme plástico termoencolhível;

c) Embalagem plástica flexível: tipo stand up pouch (sachê), confeccionada em poliéster/alumínio/polietileno de baixa densidade - 340g. Embalagem secundária: Caixa de papelão ondulado, contendo 24 sachês.

\subsection{Métodos}

A metodologia utilizada neste estudo é denominada Packaging Scorecard (Olsmats \& Dominic, 2003; Dominic, 2010), que realiza um estudo de desempenho da embalagem com base na percepção dos profissionais envolvidos na cadeia de distribuição de um determinado produto. Foi utilizada uma lista de critérios de avaliação para embalagens primárias, conforme definidos a seguir: 
Proteção oferecida ao produto (critério avaliado por Fabricante e Ponto de Venda): capacidade de proteger o produto em relação a vazamentos, contaminação e amassamentos;

Fluxo de informações (critério avaliado por Fabricante): referente às informações presentes nas embalagens que facilitam o fluxo das operações logísticas, como códigos de barras e etiquetas com informações referentes a identificação, peso e restrições;

Eficiência de volume e peso (critério avaliado por Fabricante): capacidade de proporcionar arranjos eficientes para acondicionamento em caixas e bandejas, e nos paletes para transporte e estocagem;

Operação em máquina (critério avaliado por Fabricante): refere-se à eficiência do material/embalagem na linha de produção. Esse critério contempla a aptidão da embalagem em relação a características, como: conformação do material na linha, facilidade de enchimento, fechamento e selagem;

Empilhamento (critério avaliado por Fabricante): referente à facilidade de empilhar/estocar o material da embalagem antes do acondicionamento do produto;

Custo da embalagem (critério avaliado por Fabricante): custo do material de embalagem e processo de enchimento/fechamento;

Informações sobre o produto (critério avaliado Pontos de venda): a embalagem oferece informações suficientes sobre o produto;

Quantidade e tamanho certos (critério avaliado por Pontos de venda): capacidade da embalagem de ser empilhada/arrumada nas prateleiras;

Manuseio (critério avaliado por Pontos de venda): facilidade em manusear a embalagem

Capacidade de venda (critério avaliado por Pontos de venda): capacidade de autovenda da embalagem (poder de atração na prateleira);

A aplicação do Packaging Scorecard é feita em três etapas:

Na etapa 1, os profissionais, alocados em um determinado ponto da cadeia de distribuição (fábrica ou PV), participam de uma entrevista presencial, na qual são convidados a relatar suas percepções sobre os sistemas de embalagem avaliados. Durante a entrevista, o grupo recebe um primeiro formulário que apresenta todos os possíveis conjuntos formados por pares dos critérios de avaliação, para que seja escolhida a importância relativa entre eles. Para cada par de comparação, há uma escala que varia entre Extrema Importância ou Igual Importância.

Os resultados obtidos nesse questionário foram aplicados na metodologia Analytic Hierarchy Process (AHP), para definição do Peso/Importância de cada critério. O método AHP é uma técnica de auxílio à tomada de decisão, que se baseia na caracterização de um problema através da participação dos envolvidos na tomada de decisão (Saaty \& Vargas, 2012). Para realização dos cálculos de comparação pareada com base no método AHP, foi utilizado o software Make it Rational. Disponível na versão on-line, esse software obtém os Pesos/Importâncias (hierarquização) dos critérios e o valor da Taxa de Consistência.

$\mathrm{Na}$ etapa 2, os profissionais recebem um segundo questionário, no qual (em grupo) avaliam as embalagens, em relação aos critérios de avaliação, atribuindo uma Pontuação numa escala de 1 a 9 (sendo 1 = não aprovado; 5 = aprovado; 9 = muito satisfeito). Na etapa 3, o Peso/Importância é multiplicado pela Pontuação em cada critério (para cada tipo de embalagem), obtendo-se uma Nota. A soma total das Notas equivale ao resultado de Desempenho Global da embalagem.

\subsection{Entrevistas}

A aplicação dos questionários foi realizada com profissionais de nível gerencial (supervisores e gerentes) de cada um dos pontos da cadeia de suprimentos. As entrevistas foram presenciais e realizadas com base nos preceitos do método multicritério de apoio à decisão. Nos pontos da cadeia em que havia mais de um profissional, estes foram convidados a participar de uma atividade em grupo e interagir na obtenção de pesos e notas de consenso para as embalagens avaliadas. Nos pontos em que havia apenas um profissional, os pesos e as notas foram relativos apenas à sua percepção. 
O número de entrevistados variou nos diferentes pontos da cadeia. Foram entrevistados nove profissionais na Fábrica, dois profissionais no PVV1, um profissional do PVV2 e um profissional do PVA. Essa diferença no número de entrevistados variou em função do porte do ponto da cadeia, da estrutura de cargos nos pontos e da disponibilidade dos profissionais em participar da avaliação.

\subsection{Definição dos pontos de venda}

Para esse trabalho, foi solicitado à empresa fabricante do produto a indicação de um ponto de venda varejista (PVV1) e um ponto de venda atacadista (PVA) de grande porte, ou seja, que representassem grandes movimentações de carga dentro de sua categoria e que estivessem localizados na área urbana da cidade de São Paulo. Também foi solicitada a indicação de um ponto de venda varejista (PVV2) de pequeno porte. A Tabela 2 apresenta as características de cada ponto de venda.

Tabela 2. Características de cada ponto de venda.

\begin{tabular}{cccc}
\hline \multirow{2}{*}{ Características } & \multicolumn{3}{c}{ Tipo de Ponto de Venda } \\
\cline { 2 - 4 } ZMRC & PVV1 & PVV2 & PVA \\
Tipo de cliente & Fora & Dentro & Fora \\
& Supermercado convencional & Supermercado de bairro & Atacadista \\
Origem da Entrega & CD2 onde ocorreu & CD2 onde ocorreu pré- & CD1 \\
& $\begin{array}{c}\text { pré-separação de } \\
\text { produto avariado }\end{array}$ & separação de produto & avariado \\
Local de recebimento & Docas & Calçada & Docas \\
\hline
\end{tabular}

ZMRC: Zona de Máxima Restrição de Circulação.

O PVV1 e o PVA estão localizados fora da Zona de Máxima Restrição de Circulação, o PVV2 está localizado dentro da Zona de Máxima Restrição Veicular (Figura 3).

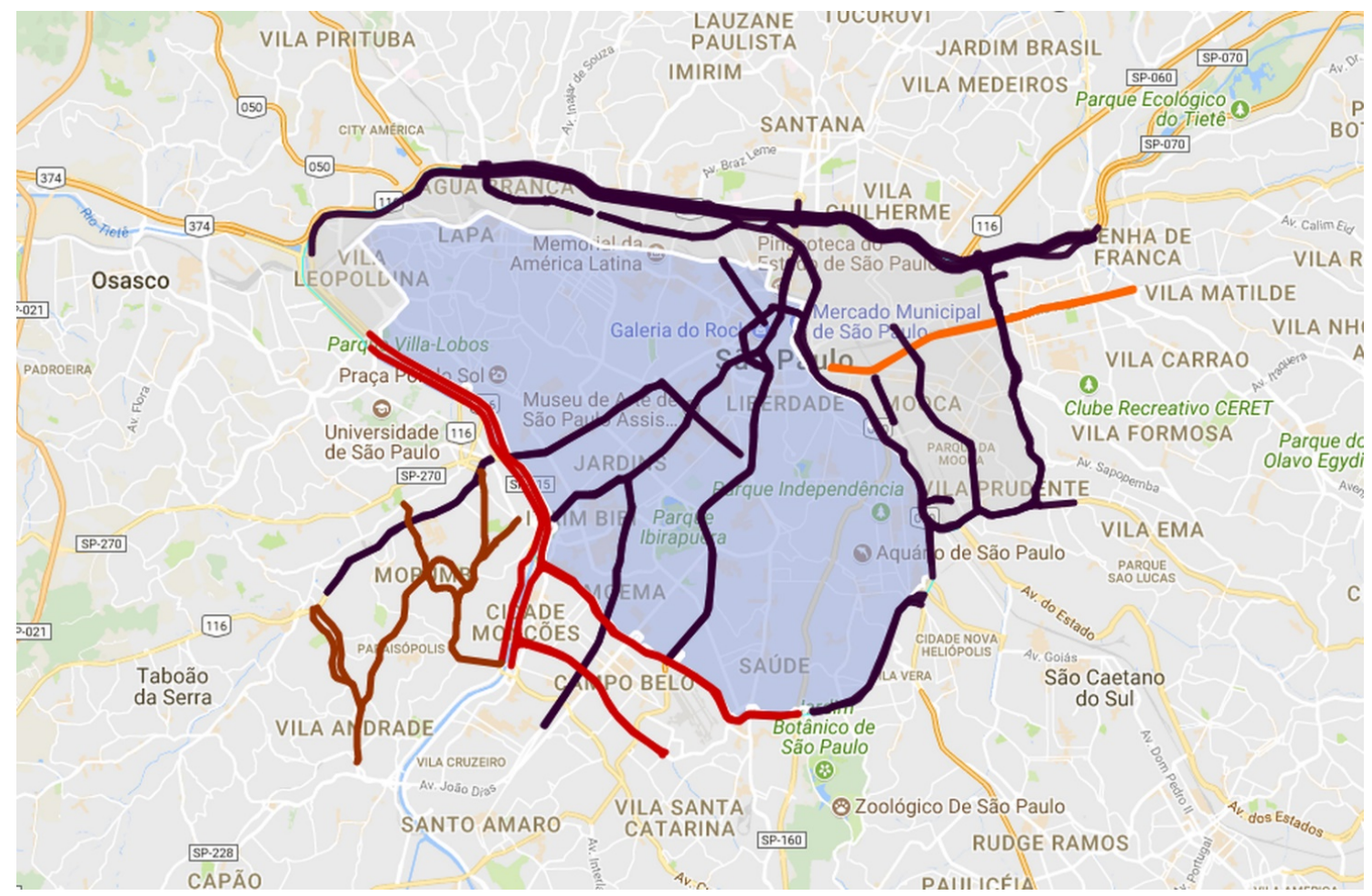

Figura 3. Zona de Máxima Restrição de Circulação (ZMRC) da cidade de São Paulo - Companhia de Engenharia de Tráfego (2018). 
A Zona de Máxima Restrição de Circulação (ZMRC) foi definida pela Companhia de Engenharia de Tráfego da cidade de São Paulo como sendo a área central urbana da cadeia de suprimentos do estudo. Por se tratar de uma área urbana, densamente povoada, apresenta todos os problemas clássicos de logística urbana, como restrições ao tipo de veículo de carga circulante, aos locais para carga e descarga, e alto nível de congestionamentos no entorno do comerciante varejista. Devido a essas características, o desempenho logístico das embalagens pode ser influenciado quando os Pontos de Venda estão localizados nessa área, pois as mesmas podem ser submetidas a movimentações e manuseios mais severos.

\section{Resultados e discussões}

Nas Tabelas 3 a 5 são apresentados os resultados obtidos nas entrevistas referentes às embalagens primárias, nos diferentes pontos da cadeia de distribuição.

Tabela 3. Resultados obtidos para as embalagens primárias na Fábrica.

\begin{tabular}{ccccc}
\hline Critérios avaliados & $\begin{array}{c}\text { Importância do } \\
\text { critério }\end{array}$ & \multicolumn{2}{c}{ Pontuação por tipo de embalagem (*) } \\
\cline { 2 - 5 } & $\mathbf{( \% )}$ & Lata & Cartonada & $\begin{array}{c}\text { Stand up } \\
\text { pouch }\end{array}$ \\
Proteção oferecida ao produto & 31,8 & 7 & 7 & 3 \\
Fluxo de informações & 33,6 & 8 & 8 & 8 \\
Eficiência de volume e peso & 3,9 & 8 & 8 & 3 \\
Operação em máquina & 13,4 & 7 & 7 & 3 \\
Empilhamento & 2,5 & 8 & 8 & 6 \\
Custo & 14,8 & 4 & 5 & 6 \\
\hline
\end{tabular}

Resultados referentes à entrevista com nove profissionais da fábrica; (*) Escala de Pontuação de 1 a 9 (sendo 1 = não aprovado; 5 = aprovado; $9=$ muito satisfeito.

Conforme apresentado na Tabela 3, na Fábrica, os critérios "Proteção oferecida ao produto" e "Fluxo de Informações" somaram $65,4 \%$ de importância, sendo, portanto, altamente relevantes para os profissionais desse ponto da cadeia. O critério "Proteção oferecida ao produto" também foi considerado importante (acima de 30\% de relevância), para o Fabricante em Estudo de Caso apresentado em Dominic (2010).

Observa-se também que as pontuações obtidas pela lata e pela embalagem cartonada foram iguais em cinco dos seis atributos avaliados, diferindo apenas no atributo "Custo". A embalagem stand up pouch apresentou as menores pontuações em todos os critérios, com exceção do critério "Fluxo de informações", no qual as três embalagens apresentaram pontuação igual.

Tabela 4. Resultados obtidos para as embalagens primárias nos diferentes Pontos de Venda.

\begin{tabular}{|c|c|c|c|c|c|}
\hline \multirow{2}{*}{ Critérios avaliados } & \multirow{2}{*}{$\begin{array}{l}\text { Ponto de } \\
\text { Venda }\end{array}$} & \multirow{2}{*}{$\begin{array}{c}\text { Importância do } \\
\text { critério } \\
(\%)\end{array}$} & \multicolumn{3}{|c|}{ Pontuação por tipo de embalagem (*) } \\
\hline & & & Lata & Cartonada & Stand up pouch \\
\hline \multirow{3}{*}{$\begin{array}{l}\text { Proteção oferecida ao } \\
\text { produto }\end{array}$} & PVV1 & 13,4 & 8 & 8 & 1 \\
\hline & PVV2 & 18,2 & 8 & 8 & 1 \\
\hline & PVA & 27,8 & 7 & 4 & 7 \\
\hline \multirow{3}{*}{$\begin{array}{l}\text { Informações sobre o } \\
\text { produto }\end{array}$} & PVV1 & 5,5 & 8 & 8 & 8 \\
\hline & PVV2 & 7,4 & 9 & 9 & 9 \\
\hline & PVA & 9,0 & 8 & 8 & 8 \\
\hline \multirow{3}{*}{$\begin{array}{l}\text { Quantidade e } \\
\text { tamanho corretos }\end{array}$} & PVV1 & 12,0 & 7 & 8 & 4 \\
\hline & PVV2 & 30,9 & 9 & 9 & 4 \\
\hline & PVA & 3,7 & 8 & 4 & 3 \\
\hline \multirow{3}{*}{ Manuseio } & PVV1 & 36,5 & 6 & 7 & 8 \\
\hline & PVV2 & 23,6 & 9 & 9 & 9 \\
\hline & PVA & 11,9 & 7 & 7 & 3 \\
\hline \multirow{3}{*}{ Capacidade de venda } & PVV1 & 32,7 & 6 & 5 & 8 \\
\hline & PVV2 & 19,9 & 6 & 7 & 9 \\
\hline & PVA & 47,5 & 6 & 4 & 8 \\
\hline
\end{tabular}

PVV1 - Resultados referentes à entrevista com dois profissionais do referido espaço; PVV2 - Resultados referentes à entrevista com um profissional do referido espaço; PVA - Resultados referentes à entrevista com um profissional do referido espaço; (*) Escala de Pontuação de 1 a 9 ( 1 = não aprovado; 5 = aprovado; 9 = muito satisfeito).

Os resultados apresentados na Tabela 4 ilustram as diferentes realidades de cada um desses comércios. 
Considerando-se uma avaliação geral das pontuações obtidas pelas embalagens nos pontos de venda, observa-se que, excluindo-se os critérios nos quais as três embalagens apresentaram a mesma pontuação, a lata apresenta seis vezes a melhor pontuação, seguida das embalagens cartonada e stand up pouch, que apresentaram cinco vezes a melhor pontuação.

O PVV1 é um supermercado de porte médio, localizado em uma área com população de, teoricamente, menor poder aquisitivo, fora da ZMRC e com grande espaço de gôndola para os molhos de tomate. Para esse PV, os critérios mais importantes são "Manuseio" e "Capacidade de venda", com pesos muito próximos (36,5 e 32,7, respectivamente). Para esses critérios, todas as embalagens apresentaram desempenho acima de nota 5 (meio da escala), sendo que a embalagem stand up pouch apresentou melhor desempenho quando comparada às outras duas embalagens.

O PVV2 é uma loja de pequeno porte, localizada na área central da cidade e dentro da ZMRC, situandose em uma região com população de, teoricamente, maior poder aquisitivo, quando comparado ao PVV1. Nesse PV, o critério de maior importância foi "Quantidade e tamanho corretos", provavelmente devido ao pequeno espaço disponível para expor o produto. Nesse critério, a embalagem stand up pouch, por ser mais difícil de ser disposta na prateleira, apresentou o pior desempenho (igual a 4), enquanto as outras duas embalagens (lata e cartonada) apresentaram desempenho máximo (igual a 9).

Para o PVA, com grande espaço de loja e vendendo tanto no atacado como no varejo, "Capacidade de venda" é o mais importante dos critérios (47,5\%), seguido pelo critério "Proteção oferecida ao produto" $(27,8 \%)$, no qual a lata e a embalagem stand up pouch apresentaram desempenho equivalente. Nesses dois critérios, a embalagem cartonada apresentou a pior nota (igual a 4, em ambos os casos).

Ainda em relação ao critério "Proteção oferecida ao produto", os resultados mostram que, para os dois PVVs, a embalagem do tipo stand up pouch apresentou Pontuação igual a 1, o que equivale a "Não aprovada". No entanto, para o PVA, essa mesma embalagem apresentou uma avaliação positiva com Nota igual a 7. Isso pode ser explicado pelo menor número de movimentações ao qual essa embalagem é submetida, uma vez que seu transporte ocorre diretamente do CD1 para o PVA. Em relação a embalagem cartonada, o PVA atribui uma nota negativa para essa embalagem, descrevendo problemas de amassamento não reversíveis da mesma.

O critério "Informações sobre o produto" apresentou as maiores notas para todas as embalagens (entre 8 e 9) e o maior consenso entre os PVs. Esse resultado pode ser explicado pelo fato de que não há diferenciação na informação fornecida entre os três tipos de embalagem.

Para o critério "Quantidade e tamanho corretos", a dificuldade em dispor a embalagem stand up pouch nas gôndolas foi identificada por todos os PVs, que apresentaram pontuações negativas (entre 3 e 4). Nesse critério, o PVA mais uma vez deu uma pontuação negativa para a embalagem cartonada, devido à presença de amassamentos que dificultaram a colocação da mesma na gôndola.

Em relação ao "Manuseio", a nota mais baixa foi dada ao stand up pouch pelo PVA, que considerou a flexibilidade da embalagem como um entrave na facilidade de movimentação da embalagem.

No critério "Capacidade de venda", a embalagem stand up pouch apresentou as maiores notas para todos os PVs. Esse resultado é claramente influenciado pelo menor preço do produto, nessa embalagem. Em 2018, através de consulta a sites de venda online, os autores constataram que o preço do molho de tomate, de uma mesma marca e quantidade de produto, acondicionado em embalagem stand up pouch, apresentou valores entre 1,5 a 2,5 vezes menor, quando comparado ao produto acondicionado em lata.

Tabela 5. Comparação entre o desempenho global das embalagens primárias.

\begin{tabular}{cccc}
\hline Local & \multicolumn{3}{c}{ Desempenho Global } \\
\cline { 2 - 4 } Fábrica & Lata & Cartonada & Stand up pouch \\
PVV1 - (Fora da ZMRC) & 7,0 & 7,1 & 5,2 \\
PVV2 - (Dentro da ZMRC) & 6,5 & 6,7 & 6,6 \\
PVA - (Fora da ZMRC) & 8,2 & 8,4 & 6,0 \\
\hline
\end{tabular}


Na metodologia Packaging Scorecard, o Desempenho Global (Tabela 5) considera a Importância e a Pontuação de cada critério para totalizar um valor geral. Dessa forma, critérios específicos que estão com uma Pontuação baixa, mas com Importância não tão expressiva, são compensados por critérios específicos que estão com Pontuação e Importância maiores. Um exemplo dessa questão pode ser observado na embalagem primária do tipo stand up pouch, a qual, nos PVV1 e PVV2, apresentou Pontuação baixa no critério "Proteção oferecida ao produto", mas que foi compensada pela Pontuação do critério "Capacidade de Venda", que apresentou maior percentual de Importância nos três pontos de venda.

Para o PVV1, os três tipos de embalagens apresentaram desempenho global muito semelhante. A Fábrica e o PVV2 apresentaram as mesmas relações decrescentes de pontuação entre as embalagens, sendo que a embalagem cartonada foi considerada mais adequada enquanto a embalagem stand up pouch apresentou o pior desempenho. No PVA, as embalagens de lata e stand up pouch apresentaram desempenho semelhante $\mathrm{e}$ melhor, quando comparadas à embalagem cartonada.

Em relação à média global de desempenho, a lata apresentou o melhor desempenho $(7,1)$, seguida pela embalagem cartonada $(6,7)$ e pela embalagem stand up pouch $(6,2)$.

\section{Conclusões}

Os resultados obtidos mostram que, para o produto e a cadeia de distribuição estudados, a lata apresentou a melhor média de desempenho global, sendo seguida pela embalagem cartonada, que apresentou o melhor desempenho em três dos quatros pontos da cadeia avaliados.

A aplicação da metodologia Packaging Scorecard permitiu duas avaliações sobre as embalagens em estudo: uma primeira avaliação é referente aos resultados de desempenho global que possibilitam uma percepção da adequação da embalagem dentro da cadeia de suprimentos. Outra contribuição da ferramenta é a observação das pontuações em cada critério, as quais permitem a identificação de características específicas das embalagens em que podem ser realizadas melhorias. Essas informações, em conjunto, podem ajudar os tomadores de decisão a considerar ou não mudanças nas especificações de embalagens.

\section{Agradecimentos}

Os autores agradecem ao Conselho Nacional de Desenvolvimento Científico e Tecnológico (CNPq), ao Laboratório de Aprendizagem em Logística e Transportes (LALT - UNICAMP) e ao Instituto de Tecnologia de Alimentos (ITAL) pelo apoio prestado a este estudo.

\section{Referências}

Arvanitoyannis, I. S. (2008). Waste management in food packaging industries. In I. S. Arvanitoyannis. Waste management for the food industries (pp. 941-1045, Chap. 15). Burlington: Academic Press. http://dx.doi.org/10.1016/B978-012373654-3.500183.

Chan, F. T. S., Chan, H. K., \& Choy, K. L. (2006). A systematic approach to manufacturing packaging logistics. International Journal of Advanced Manufacturing Technology, 29(9-10), 1088-1101. http://dx.doi.org/10.1007/s00170-005-2609-x

Companhia de Engenharia de Tráfego - CET. (2018). São Paulo. Recuperado em 15 de setembro de 2018, de http://www.cetsp.com.br

Dezi, G., Dondi, G., \& Sangiorgi, C. (2010). Urban freight transport in Bologna: planning commercial vehicle loading/unloading zones. Procedia - Social and Behavioral Sciences, 2(3), 5990-6001. https://doi.org/10.1016/j.sbspro.2010.04.013.

Dominic, C. (2010). Packaging logistics performance and how to evaluate the packaging performance by applying the tool packaperforma. In Proceedings of the 17th lapri World Conference on Packaging (pp. 245-250). Delaware, USA: SCIRP.

García-Arca, J., Gonzales-Portela Garrido, A. T., \& Prado, P. (2017). "Sustainable packaging logistics". The link between sustainability and competitiveness in supply chains. Sustainability, 9(7), 1098. http://dx.doi.org/10.3390/su9071098

Johansson, K., Karlsson, A. L., Olsmats, C., \& Tiliander, L. (1997). Packaging logistics (86 p.). Kista, Sweden: Packforsk. 
Desempenho logístico de embalagens para molho de tomate: um estudo de caso na cidade de São Paulo, Brasil

Noletto, A. P. R. et al.

Kye, D., Lee, J., \& Lee, K. D. (2013). The perceived impact of packaging logistics on the efficiency of freight transportation (EOT). International Journal of Physical Distribution \& Logistics Management, 43(8), 707-720.

Lambert, D. M., Stock, J. R., \& Vantine, J. G. S. (1998). Administração estratégica da logística (912 p.). São Paulo: Vantine Consultoria.

Lockamy III, A. (1995). A conceptual framework for assessing strategic packaging decisions. The International Journal of Logistics Management, 6(1), 51-60.

Nilsson, F., Fagerlund, M., \& Körner, J. (2013). Globally standardised versus locally adapted packaging: a case study at Sony Ericsson Mobile Communications AB. International Journal of Retail \& Distribution Management, 41(5), 396-414. http://dx.doi.org/10.1108/IJRDM-05-2013-0091

Olsmats, C., \& Dominic, C. (2003). Packaging scorecard: a packaging performance evaluation method. Packaging Technology \& Science, 16(1), 9-14. http://dx.doi.org/10.1002/pts.604

Peres, C. R. G. (2006). Análise do método de custeio baseado em atividades aplicado à logística de distribuição (Dissertação de mestrado). Escola de Engenharia de São Carlos, Universidade de São Paulo, São Carlos.

Rundh, B. (2013). Linking packaging to marketing: how packaging is influencing the marketing strategy. British Food Journal, 115(11), 1547-1563.

Saaty, T. L., \& Vargas, L. G. (2012). Models, methods, concepts \& applications of the analytic hierarchy process (2nd ed, 345 p., Vol. 175, International Series in Operations Research \& Management Science). New York: Springer. http://dx.doi.org/10.1007/978-1-4614-3597-6

Sousa, V. (2013). Molhos de tomate sachês impulsionam vendas. Supermercado Moderno. Recuperado em 15 de março de 2013, de http://www.sm.com.br/Editorias/Categorias/Molhos-de-tomate-sachesimpulsionam-vendas-9008.html

Supermercado Moderno. (2016). Mercearia de alto giro - atomatados. Recuperado em 15 de junho de 2017, de http://www.sm.com.br/resultado-de-busca-gps/mercearia-de-alto-giro/atomatados

Financiamento: Nenhum.

Received: July 24, 2017; Accepted: Nov. 25, 2018 